\title{
An Empirical Model of Wage Indexation Provisions in Union Contracts
}

\section{David Card}

The Journal of Political Economy, Vol. 94, No. 3, Part 2: Hoover Institution Labor Conference. (Jun., 1986), pp. S144-S175.

Stable URL:

http://links.jstor.org/sici?sici=0022-3808\%28198606\%2994\%3A3\%3CS144\%3AAEMOWI\%3E2.0.CO\%3B2-1

The Journal of Political Economy is currently published by The University of Chicago Press.

Your use of the JSTOR archive indicates your acceptance of JSTOR's Terms and Conditions of Use, available at http://www.jstor.org/about/terms.html. JSTOR's Terms and Conditions of Use provides, in part, that unless you have obtained prior permission, you may not download an entire issue of a journal or multiple copies of articles, and you may use content in the JSTOR archive only for your personal, non-commercial use.

Please contact the publisher regarding any further use of this work. Publisher contact information may be obtained at http://www.jstor.org/journals/ucpress.html.

Each copy of any part of a JSTOR transmission must contain the same copyright notice that appears on the screen or printed page of such transmission.

The JSTOR Archive is a trusted digital repository providing for long-term preservation and access to leading academic journals and scholarly literature from around the world. The Archive is supported by libraries, scholarly societies, publishers, and foundations. It is an initiative of JSTOR, a not-for-profit organization with a mission to help the scholarly community take advantage of advances in technology. For more information regarding JSTOR, please contact support@jstor.org. 


\title{
An Empirical Model of Wage Indexation Provisions in Union Contracts
}

\section{David Card}

\author{
Princeton University
}

\begin{abstract}
This paper describes the responses of index-linked wage rates to concurrent price increases for a sample of Canadian union contracts and then analyzes these responses in terms of a simple model of indexation to the aggregate price level. The model highlights the importance of aggregate price movements in conveying information about industry-specific prices. The empirical analysis confirms that industry-specific correlations between input and output prices and the consumer price index are important determinants of the flexibility of wages to prices across indexed contracts.
\end{abstract}

A distinctive feature of North American labor contracts is their provision for a link between contractual wage rates and the consumer price index (CPI). At present, just under 60 percent of workers in large union contracts in the United States are covered by some form of indexation clause. ${ }^{1}$ The response of index-linked wage rates to price increases is important not only for the structure of wages in the union

I am grateful to Robert Hall, James Heckman, and a referee for their perceptive comments and suggestions. I also thank David Wilton for making available the data in this study. Financial assistance was provided by the Social Sciences and Humanities Research Council of Canada, the Social Science Research Council, and the Industrial Relations Section of Princeton University.

${ }^{1}$ See Davis (1983). Unfortunately, no information is available on the coverage of indexation clauses in smaller union contracts (fewer than 1,000 workers) or in the nonunion sector. It is generally believed that escalation provisions are rare in the nonunion sector (e.g., Douty 1975). On this basis, perhaps no more than 10 percent of all U.S. workers are covered by cost-of-living provisions. 
sector but also for macroeconomic wage and price dynamics. ${ }^{2}$ This paper presents estimates of the elasticity of wages rates with respect to concurrent price increases for a sample of indexed Canadian contracts and then analyzes these estimated elasticities in terms of a simple theoretical model of wage indexation. The model relates differences in the price response of index-linked wage rates across industries to differences in the correlations between industry-specific prices and the aggregate price index.

Section I contains a brief description of escalation clauses in North American labor contracts. It is argued that the diverse indexation formulas observed in these contracts are usefully summarized by the marginal response of contractual wage rates to the CPI. The model in Section II is motivated by the wide cross-sectional distribution of this response. According to the model, the elasticity of escalated wage increases with respect to concurrent price increases varies across industries depending on the extent to which industry-specific prices move with the CPI. This insight is tested in Section III. The elasticity of the indexed wage rate with respect to the CPI in each contract is expressed as a function of the estimated correlations between the CPI and the prices specific to the industry of that contract, other industry variables, and parameters representing the preferences of workers and firms. The model provides a parsimonious but successful explanation for the industry pattern of the responsiveness of indexed wages to price increases and a simple interpretation of the link between industry-specific variables and the escalation provisions in each industry.

\section{Characteristics of Wage Escalators in Major Union Contracts}

Wage indexation provisions emerged in North American labor markets over 100 years ago. ${ }^{3}$ The form of current indexed labor contracts was largely influenced by the historic 1948 agreement between General Motors (GM) and the United Auto Workers (UAW), however. ${ }^{4}$ With few exceptions, present-day indexed contracts have adopted the pattern of the original GM-UAW accord. First, they combine both noncontingent and contingent wage increases over the life of the

${ }^{2}$ This latter aspect of escalation clauses is emphasized by Gray (1976) and Fischer (1977).

${ }^{3}$ Indexed wage rates were instituted in the iron industry around Pittsburgh in the 1860 s. Wages were linked to the price of pig iron, with a 1 percent increase in iron prices leading to approximately a 0.5 percent increase in wages (see Taft 1945).

${ }^{4}$ Garbarino (1962) describes the origins of the GM-UAW contract and its impact on subsequent collective bargaining arrangements. 
contract. Second, they link absolute wage increases to the absolute increase in the CPI above a contractually specified base level. ${ }^{5}$ In many contracts, including the original GM-UAW agreement, the price level at the signing date of the contract forms the basis for subsequent index-linked wage increases. ${ }^{6}$ In other contracts, however, the base level is the price level at a date midway through the contract or, less frequently, a percentage markup on the price level at the start of the contract. Third, most escalator clauses generate the same absolute wage increases for all workers in the contract, regardless of the level of their wages.

Formally, these features imply that the wage rate of a particular group of workers in the contract at time period $t, w(t)$, consists of the noncontingent wage rate for that group at period $t, w^{n}(t)$, and a contingent component that is proportional to the difference between the price level at $t, p(t)$, and the base price level, $p^{\tau}$ :

$$
w(t)=w^{n}(t)+\max \left\{0, \alpha\left[p(t)-p^{\tau}\right]\right\} .
$$

In this equation $\alpha$ represents the wage increase awarded by the escalator per point increase in the CPI. A typical indexed labor contract specifies a noncontingent wage schedule for each group of workers in the contract, a base price level for the calculation of contingent wage increases, and an index-linked wage increase per point increase in the CPI. ${ }^{7}$ In addition, some contracts specify a maximum absolute increase due to escalation.

On the basis of equation (1), there are several alternative characterizations of contractual escalation formulas. For example, the marginal elasticity of indexation in the $t$ th period of the contract is simply $\alpha[p(t) / w(t)]$ if the escalator is operative and zero otherwise. One particularly useful way to summarize escalation formulas is in terms of the marginal elasticity of escalation relative to the wage rate at the start of the contract (period 0$): e \equiv \alpha[p(0) / w(0)]$. In contracts with multiple wage rates that provide the same index-linked wage increase for all workers, the marginal elasticity of indexation must be defined relative

\footnotetext{
${ }^{5}$ Virtually all present-day escalation clauses link wages to the CPI. An interesting variant occurred in the automobile industry in the 1960s and 1970s where wages were linked to a weighted average of the U.S. (.90) and Canadian (.10) indexes. Approximately 95 percent of indexed agreements in the United States and Canada link absolute (as opposed to percentage) wage increases to absolute price changes. Douty (1975, p. 41) states that this percentage remained roughly constant in the United States between 1963 and 1975. Formulas that link percentage increases in wages to percentage increases in prices, while rare in the manufacturing industries, are more widespread in the government sector and the service industries in Canada.

6 This is true of about 55 percent of the indexed contracts written in the Canadian manufacturing sector between 1968 and 1975 .

${ }^{7}$ If wages are linked to price increases after a certain date $\tau$, then $p^{\tau}=p(\tau)$ is just the price level at that date (and is uncertain at the signing of the contract).
} 
to a particular wage rate. Obviously, the marginal elasticity of indexation is lower for more highly paid workers. As a consequence, escalation provisions have typically contributed toward the erosion of skill differentials during the life of the contract. ${ }^{8}$

The marginal elasticity measure $e$ provides an ex ante estimate of the overall elasticity of wage increases to price increases during the life of the contract, provided that the base price level $p^{\tau}$ and the noncontingent deferred wage increases in the contract are related in a simple way. Observe that a linear escalation formula with no delay in the start of indexation generates a wage-price relationship of the form

$$
w(t)=w(0)+\alpha[p(t)-p(0)],
$$

where $w(0)$ is the wage rate and $p(0)$ is the price level at the start of the contract. ${ }^{9}$ On the assumption that price level growth during the contract period is less than (say) 20 percent, this is approximately equivalent to the constant elasticity wage formula

$$
\log w(t)=\log w(0)+e[\log p(t)-\log p(0)],
$$

where $e=\alpha[p(0) / w(0)] .{ }^{10}$ Therefore, in contracts with no delay in the start of wage escalation, $e$ is an appropriate estimator of the elasticity of nominal contractual wages with respect to price increases over the life of the contract. On the other hand, the same wage-price relationship emerges in the presence of delayed indexation provisions if the wage rate at the start of indexation, $w(\tau)$, is related to the base price, $p^{\tau}$, by $^{11}$

$$
\frac{w(\tau)-w(0)}{w(0)}=e \frac{p^{\tau}-p(0)}{p(0)} .
$$

${ }^{8}$ For example, an analysis of the wage rates of the highest- and lowest-paid workers in 281 indexed contracts written between 1968 and 1975 in Canada reveals that indexation provisions reduced the relative wages of the highest-paid workers in the contracts by some 2.5 percent per year, on the average (see Card 1983).

${ }^{9}$ Noncontingent deferred increases are ignored. In contracts with indexation clauses that take effect immediately after the start of the contract, noncontingent deferred increases are typically small: $2-3$ percent per year in the case of many automobile industry contracts, e.g.

${ }^{10}$ This wage-price formula is also equivalent to one that links wage increases to the difference between the realized price level and the expected price level, provided that the wage rate at the start of the contract is suitably chosen.

${ }^{11}$ Consider a delay in indexation until prices are $p^{\tau}$, coupled with a noncontingent wage increase that gives a wage rate $w(\tau)$ at the start of indexation. Once indexation is under way, the wage rate is

$$
\begin{aligned}
w(t)= & w(\tau)+\alpha\left[p(t)-p^{\tau}\right] \\
= & w(0)+\alpha[p(t)-p(0)] \\
& +w(0)\left[\frac{w(\tau)-w(0)}{w(0)}-\alpha \frac{p(0)}{w(0)} \frac{p^{\tau}-p(0)}{p(0)}\right] .
\end{aligned}
$$


According to this interpretation, the role of noncontingent, deferred increases in the contract is to compensate for price increases that occur prior to the start of indexation. If the elasticity of noncontingent deferred wage increases with respect to price increases prior to indexation equals the marginal elasticity of contingent wage increases with respect to price increases during indexation, then the total elasticity of wage increases with respect to price increases over the life of the contract is approximately equal to the (observable) marginal elasticity $e$.

The choice between larger noncontingent increases, coupled with longer delays in the start of indexation, and smaller noncontingent increases, coupled with shorter delays in the start of indexation, is problematical. ${ }^{12}$ In any case, the degree of inflation protection provided by the combination of contingent and noncontingent deferred increases is approximately $e$, assuming that the noncontingent wage increases in the contract are linked to the delay in indexation by equation (2). In the absence of any model of noncontingent deferred increases in indexed contracts, I will use the marginal elasticity $e$ as an estimate of the ex ante desired responsiveness of contractual wage rates to concurrent price increases for escalator clauses taking the form of equation (1). Although this measure abstracts from desired productivity-linked increases in real wage rates over the life of the contract and ignores cap provisions that limit the size of escalated wage increases, at the very least it summarizes one important dimension of escalated contracts. ${ }^{13}$

Figure 1 presents a frequency distribution of the marginal elasticity measure $e$ from a sample of 189 indexed labor contracts written in the Canadian manufacturing sector between 1968 and $1975 .{ }^{14}$ These

${ }^{12}$ In Canada during the early 1970s, e.g., the UAW wrote many contracts with no delay in indexation and relatively small noncontingent increases. The United Steelworkers, on the other hand, wrote many contracts with long delays in indexation and relatively large noncontingent deferred increases (see Card 1983, table 2).

${ }^{13}$ The most widely used summary statistic for describing escalation clauses is the ratio of contingent wage increases over the contract period to the growth in the price level over the same period. Obviously, however, this ratio understates the degree of inflation protection intended by the contracting parties for contracts with delayed escalation clauses. In such contracts, some fraction of expected price level growth during the contract period is incorporated into the noncontingent deferred increases in the contract.

${ }^{14}$ The data were drawn from individual contract extracts reported in various issues of the Collective Bargaining Review, published by Labour Canada. I am grateful to David Wilton for making available the contract extracts. From October 1967 to October 1975 there were 1,405 major contracts (with more than 500 employees) signed in the Canadian private sector. Among these, 385 contained cost-of-living allowance clauses. When nonmanufacturing contracts and contracts with incomplete data are excluded, there is a usable sample of 189 contracts drawn from 44 three-digit manufacturing industries. Of these, 108 contracts were written by firms with two or more contracts in the sample. 


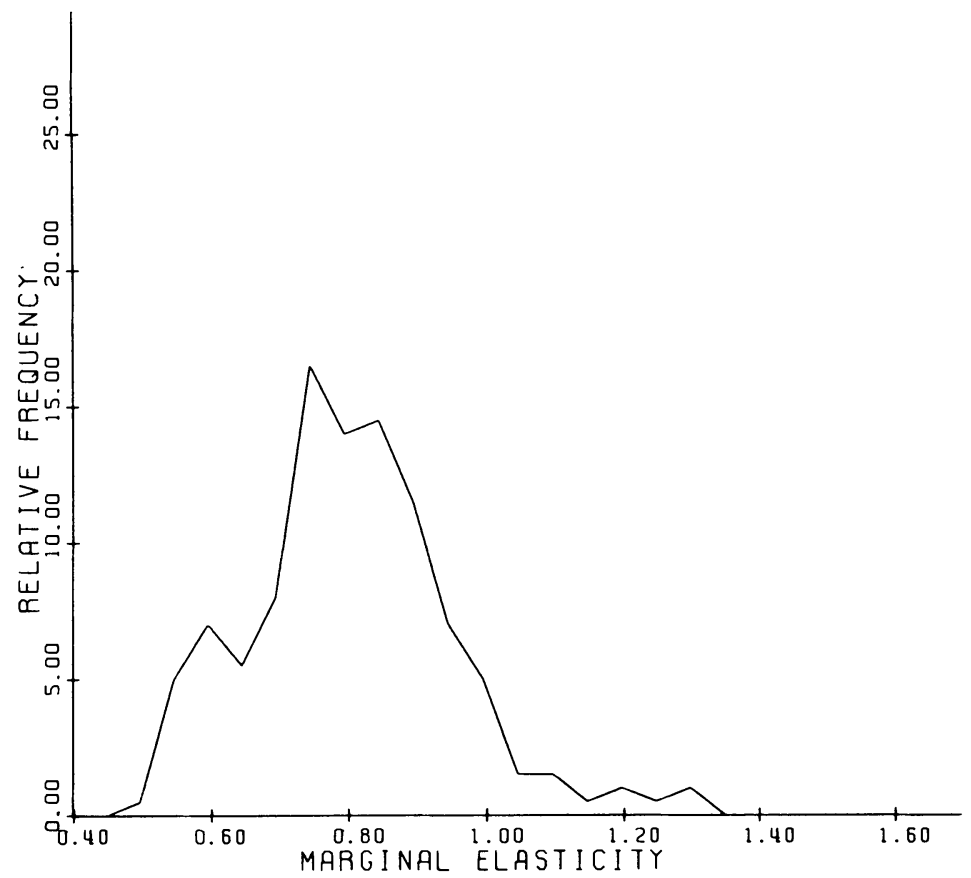

FIG. 1.-Frequency distribution of the marginal elasticity of indexation

elasticities are defined for a weighted average of the highest and lowest wage rates in each contract. ${ }^{15}$ Marginal elasticities for unskilled workers are generally 7-12 percent higher than those in figure 1, while marginal elasticities for highly skilled workers are generally $10-$ 15 percent lower. The figure illustrates two important facts. First, marginal elasticities are generally between .75 and .95 , although there are contracts with marginal elasticities as low as one-half and a significant number of contracts with marginal elasticities in excess of unity. ${ }^{16}$ Second, there is substantial dispersion in marginal elasticities. An analysis of variance, however, reveals that a large fraction of this dispersion is attributable to the industry of the contract. In fact, threedigit industry fixed effects explain over 60 percent of the cross-

${ }^{15}$ The contract extracts report only the highest and lowest wage rates in each contract. Furthermore, they give no information on the skill composition of the contractual labor force. Skill proportions were inferred from three-digit industry data. The proportion of workers earning the highest wage rate (usually a rate paid to skilled tradesmen) was set equal to the industrywide proportion of craftsmen in the total employment of craftsmen, operatives, and laborers.

${ }^{16}$ Ten percent of the contracts have a marginal elasticity for the average wage rate in excess of unity. It is interesting to note that the marginal elasticity of indexation and the probability that the escalator contains a cap provision on escalated wage increases are negatively correlated in this sample. 
sectional variation in marginal escalation elasticities. On the other hand, the within-industry distribution of marginal escalation elasticities is largely unsystematic. ${ }^{17}$ These observations suggest that a model of indexation based on industry-specific determinants of the responsiveness of contractual wage rates to aggregate price increases can explain a significant share of the dispersion of marginal elasticities illustrated in figure 1 . A simple version of such a model is presented in the next section and is tested against the data in Section III.

\section{A Model of Wage Indexation}

Assume that a union and a firm bargain over a contingent wage schedule that links the wage rate in the contract to the aggregate price level. Assume further that the firm sets employment in the contract period subject to the wage rate and the prices it faces for inputs and outputs. ${ }^{18}$ The basic idea of the model is this: If movements in the aggregate price level convey information on contemporaneous shifts in the demand and supply of labor to the contract, then the wage escalator will vary the contractual real wage rate with the realization of aggregate prices. In particular, if increases in aggregate prices signal an increase in the demand for labor or, alternatively, an increase in the alternative opportunities for workers, then the real wage rate will increase with the price level. On the other hand, if aggregate price increases signal a decrease in the demand for labor or, alternatively, a downward shift in the supply curve of labor, then the real wage rate will decrease with increases in the price level.

The ability to infer market-specific prices from the observed aggregate price level implies that the elasticity of nominal wage escalation with respect to the aggregate price level varies across industries, depending on the statistical relationship between industry-specific prices and the aggregate price level. Nevertheless, this model cannot answer a more fundamental question: Why not index-link wages directly to market-specific prices? Although there is some historical precedent

${ }^{17}$ When three-digit industry effects are controlled for, an $F$-test for the significance of firm fixed effects has a marginal significance level of just over 5 percent. The withinindustry distribution of escalation elasticities is also uncorrelated with the length of the contract, the identity of the union, whether the escalator is a new provision in the collective agreement, or the unemployment rate at the signing date of the contract.

${ }^{18}$ It is well known that unilateral employment determination by the firm does not generally result in wage-employment pairs on the contract curve between the union and the firm (see, e.g., Leontief 1946). An alternative framework is to assume that wages and employment are jointly determined. For recent attempts to test between these competing paradigms, see Brown and Ashenfelter and MaCurdy and Pencavel, both in this issue. 
for indexing wages to industry selling prices, it remains an interesting puzzle as to the nearly universal practice of escalation to the CPI. ${ }^{19}$ The approach taken here is to assume that wages are linked to the CPI and then to derive and test the implications of the model for observed marginal elasticities of indexation in contracts where wages are indexed to the CPI. The model cannot explain why wages are linked exclusively to the CPI, only how they are linked to aggregate prices in the presence of market-specific prices.

For simplicity, assume that the contract lasts for 1 period and takes effect immediately after the bargaining period. Let $L$ represent the level of employment during the contract period, let $\omega$ represent the contractual real wage, and let $a$ represent the alternative real wage available to employees during the contract period. Assume that the preferences of the union are represented by the expected value of the function

$$
U(\omega, L, a)=u(a)+\frac{L}{L_{0}}\left[u(\omega)-u(a) \frac{1}{1+\epsilon}\left(\frac{L}{L_{0}}\right)^{\epsilon}\right],
$$

where $u(x)=[1 /(1-\delta)] x^{1-\delta}$ has the interpretation of a constant relative risk aversion utility function and $L_{0}$ has the interpretation of a reference level of employment. ${ }^{20}$ This function contains a number of well-known union preference functions as special cases. For example, if $\epsilon=0$, then

$$
U(\omega, L, a)=\frac{L}{L_{0}} u(\omega)+\left(1-\frac{L}{L_{0}}\right) u(a),
$$

which gives the expected utility of employment when $L_{0}$ represents total union membership and workers are allocated randomly between contractual and alternative employment. On the other hand, if $u(x)=$ $x$, then equation (3) can be written as

$$
U(\omega, L, a)=a+\left(\frac{1}{L_{0}}\right)\left[\omega L-a \int_{0}^{L}\left(\frac{t}{L_{0}}\right)^{\epsilon} d t\right]
$$

and union preferences depend on the difference between the wage bill and the opportunity cost of employment, assuming that the supply price of workers to the contract is $a\left(L / L_{0}\right)^{\epsilon}$.

On the firm's side, assume that production is Cobb-Douglas with

${ }^{19}$ In one recent contract between $3 \mathrm{M}$ Corp. and the Oil and Atomic Workers, wage increases are linked to average wage increases reported in a survey of comparable workers.

${ }^{20}$ According to (3), the marginal utility of contractual wages is $L u^{\prime}(\omega)$, while the marginal utility of contractual employment is $u(\omega)-u(a)\left(L / L_{0}\right)^{\epsilon}$. The function (3) is quasi-concave for all $\omega, a$, and $L$ such that the marginal utility of contractual employment is positive. 
two inputs: labor and nonlabor inputs. It is convenient to parameterize the production function in terms of the elasticities of labor demand with respect to wages and nonlabor input prices. Let $-\beta$ represent the former and let $-\eta$ represent the latter. The assumption that production is Cobb-Douglas implies $\beta>1$ and $\eta>0$. Assuming that the firm sells its output competitively at the price $\theta$ and purchases nonlabor inputs at the price $q$, profits during the contract period are proportional to

$$
\pi(\theta, \omega, q)=\frac{1}{\beta-1} \theta^{\eta+\beta} \omega^{1-\beta} q^{-\eta} .
$$

Finally, assume that the owners of the firm evaluate the contract in terms of the expectation of $v(\pi)$, where $v$ is a constant relative risk aversion utility function with relative risk aversion parameter $\gamma$.

From the perspective of the bargaining period, an optimal wage escalator is one that maximizes the expected utility of profits, subject to a minimum expected utility requirement for workers. This is equivalent to maximizing

$$
E[v(\pi)+\lambda U(\omega, L, a)]
$$

for a fixed positive number $\lambda$, where expectations are taken with respect to aggregate prices, the alternative real wage, and the prices of output and nonlabor inputs. Since

$$
E[v(\pi)+\lambda U(\omega, L, a)]=E E[v(\pi)+\lambda U(\omega, L, a) \mid p],
$$

an optimal wage escalator maximizes

$$
E[v(\pi)+\lambda U(\omega, L, a) \mid p]
$$

at each aggregate price level $p$ with respect to the real wage rate at $p$. Following this strategy, the first-order condition for the real contractual wage rate at the price level $p$ is

$$
E\left[v^{\prime}(\pi) \frac{\partial \pi}{\partial \omega}+\lambda \frac{\partial U}{\partial \omega}(\omega, L, a)+\lambda \frac{\partial U}{\partial L}(\omega, L, a) \frac{\partial L}{\partial \omega} \mid p\right]=0,
$$

where $\partial L / \partial \omega$ represents the derivative of the demand for labor with respect to the wage rate $\omega$. This equation requires that the expected marginal utilities of workers and owners be in constant proportion across all realizations of the aggregate price level. Since employment is set by the firm, the marginal utility of an increase in wages from the point of view of the union consists of two components: a direct positive effect and an indirect negative effect via the employment effect of the wage change.

Given a joint distribution for the prices in the model, the first-order 
condition (4) is readily evaluated. For simplicity, assume that prices in the contract period have a joint lognormal distribution with

$$
\begin{array}{lll}
E(\log p)=\log \bar{p} & \operatorname{var}(\log p)=\sigma_{p}^{2} \\
E(\log \theta)=\log \bar{\theta} & \operatorname{var}(\log \theta)=\sigma_{1}^{2} \\
E(\log q)=\log \bar{q} & \operatorname{var}(\log q)=\sigma_{2}^{2} \\
E(\log a)=\log \bar{a} & \operatorname{var}(\log a)=\sigma_{3}^{2}
\end{array}
$$

and

$$
\begin{aligned}
& \text { correlation }(\log p, \log \theta)=\rho_{1} \\
& \text { correlation }(\log p, \log q)=\rho_{2} \\
& \text { correlation }(\log p, \log a)=\rho_{3} .
\end{aligned}
$$

Furthermore, assume that the conditional distributions of $\theta, q$, and $a$, given aggregate prices, are independent. ${ }^{21}$ Under these assumptions, the conditional expectation of employment, given the aggregate price level $p$, is

$$
\begin{aligned}
E(L \mid p)= & \omega^{-\beta} E\left(\theta^{\beta+\eta} \mid p\right) E\left(q^{-\eta} \mid p\right) \\
= & \omega^{-\beta} \bar{\theta}^{\beta+\eta} \exp \left[(\beta+\eta) r_{1} \log \left(\frac{p}{\bar{p}}\right)+1 / 2(\beta+\eta)^{2} \sigma_{1}^{2}\left(1-\rho_{1}^{2}\right)\right] \\
& \times \bar{q}^{-\eta} \exp \left[-\eta r_{2} \log \left(\frac{p}{\bar{p}}\right)+1 / 2 \eta^{2} \sigma_{2}^{2}\left(1-\rho_{2}^{2}\right)\right],
\end{aligned}
$$

where

$$
r_{1}=\frac{\operatorname{cov}(\log \theta, \log p)}{\operatorname{var}(\log p)}=\frac{\rho_{1} \sigma_{1}}{\sigma_{p}}
$$

is the regression coefficient of unanticipated changes in the log of the industry selling price on unanticipated changes in the log of the aggregate price level and

$$
r_{2}=\frac{\operatorname{cov}(\log q, \log p)}{\operatorname{var}(\log p)}=\frac{\rho_{2} \sigma_{2}}{\sigma_{p}}
$$

is the regression coefficient of innovations in the log of the industry input price on innovations in the log of the aggregate price level. ${ }^{22} \mathrm{By}$

${ }^{21}$ This simplifying assumption implies that the covariance of $\log \theta$ and $\log q$ arises solely from their joint covariance with $\log p$. Formally, it requires $\operatorname{cov}(\log \theta, \log q)=$ $\operatorname{cov}(\log \theta, \log p) \operatorname{cov}(\log q, \log p) / \operatorname{var}(\log p)$.

22 These formulas follow from the formula in App. A. 
the same token, the conditional expectation of the utility of employment at the alternative wage rate $a$ is

$$
\begin{aligned}
E[u(a) \mid p]= & \frac{1}{1-\delta} E\left(a^{1-\delta} \mid p\right) \\
= & \frac{1}{1-\delta} \bar{a}^{1-\delta} \\
& \times \exp \left[(1-\delta) r_{3} \log \left(\frac{p}{\bar{p}}\right)+1 / 2(1-\delta)^{2} \sigma_{3}^{2}\left(1-\rho_{3}^{2}\right)\right],
\end{aligned}
$$

where

$$
r_{3}=\frac{\operatorname{cov}(\log a, \log p)}{\operatorname{var}(\log p)}=\frac{\rho_{3} \sigma_{3}}{\sigma_{p}}
$$

is the regression coefficient of unanticipated changes in the log of the alternative real wage on unanticipated changes in the log of the aggregate price level. Substituting these expressions into equation (4) yields the simplified first-order condition recorded as equation (B3) in Appendix B.

Since the first-order condition for the contractual wage rate $\omega(p)$ holds across all realizations of the aggregate price level, equation (4) can be differentiated with respect to $p$ to obtain the derivative of the wage escalator, $\omega^{\prime}(p)$. If the conditional distribution of alternative wages and input and output prices is independent of $p$, then equation (4) is independent of the aggregate price level and $\omega^{\prime}(p)=0$, or, equivalently, the elasticity of the nominal contractual wage rate with respect to the aggregate price level is unity. More generally, however, movements in the aggregate price level signal movements in alternative wages or firm-specific prices. In response to changes in the conditional inferences of supply and demand conditions for labor and the profitability of the firm, the contractual wage rate adjusts with aggregate prices to restore the first-order condition. Some manipulation (see App. B) establishes that the elasticity of the real contractual wage rate with respect to changes in aggregate prices during the contract period is given by

$$
\frac{p}{\omega} \omega^{\prime}(p)=\tilde{c}_{1}(p) r_{1}+\tilde{c}_{2}(p) r_{2}+\tilde{c}_{3}(p) r_{3},
$$

where

$$
\begin{array}{r}
\tilde{c}_{1}(p)=(\beta+\eta) \frac{\gamma(1-\delta-\beta) \Psi(p)+\beta(\gamma+\epsilon) \phi(p)}{[\delta+\gamma(\beta-1)](1-\delta-\beta) \Psi(p)}, \\
+\beta[\gamma(\beta-1)+1+\epsilon \beta] \phi(p)
\end{array}
$$




$$
\begin{aligned}
\tilde{c}_{2}(p)= & -\frac{\eta}{\beta+\eta} \tilde{c}_{1}(p), \\
\tilde{c}_{3}(p)= & \frac{\beta(1-\delta) \phi(p)}{[\delta+\gamma(\beta-1)](1-\delta-\beta) \Psi(p)}, \\
& \quad+\beta[\gamma(\beta-1)+1+\epsilon \beta] \phi(p)
\end{aligned}
$$

with

$$
\Psi(p)=\left(\frac{\omega}{\bar{a}}\right)^{1-\delta} E\left[\left(\frac{a}{\bar{a}}\right)^{1-\delta} \mid p\right]^{-1}
$$

and

$$
\begin{aligned}
\phi(p)= & E\left[\left(\frac{L}{L_{0}}\right)^{\epsilon} \mid p\right] \exp \left[\epsilon(\beta+\eta)^{2} \sigma_{1}^{2}\left(1-\rho_{1}^{2}\right)\right. \\
& \left.+\epsilon \eta^{2} \sigma_{2}^{2}\left(1-\rho_{2}^{2}\right)\right] .
\end{aligned}
$$

The second-order condition for $\omega(p)$ requires that the function $\tilde{c}_{3}(p)$ be positive.

According to equation (5), the elasticity of the escalated wage rate is a weighted sum of the three regression coefficients that translate observations on the aggregate price level into inferences about the real prices of outputs, nonlabor inputs, and the alternative wage rate. The form of the functions $\tilde{c}_{1}, \tilde{c}_{2}$, and $\tilde{c}_{3}$ reflects two distinct roles for the contractual wage. First, since employment is set unilaterally by the firm, the wage acts as a proxy for the opportunity cost of employment. The latter depends on inferences of the alternative wage and also on the level of demand for labor, to the extent that the opportunity cost schedule is upward sloping (i.e., $\epsilon>0$ ). Second, the wage represents a transfer payment between owners and workers. If either party is risk averse, the wage performs an insurance function by stabilizing the profits of owners or the expected utility of workers.

The general expression for the elasticity of indexation given by equation (5) simplifies dramatically if both parties are risk neutral. In that case, the role of the contract wage is simply to mimic the marginal cost of employment, and insurance considerations are absent from the wage function. Substituting $\delta=\gamma=0$ into equation (5) yields ${ }^{23}$

$$
\frac{p}{\omega} \omega^{\prime}(p)=\frac{\epsilon(\beta+\eta)}{1+\epsilon \beta} r_{1}-\frac{\epsilon \eta}{1+\epsilon \beta} r_{2}+\frac{1}{1+\epsilon \beta} r_{3} .
$$

Given risk neutrality, the elasticity of indexation is constant for all prices and independent of either the expected relative wage gap $\Psi(p)$

${ }^{2: 3}$ Equation (6) represents a generalization of the indexation formula analyzed by Blanchard (1979). 
or the expected level of contractual employment $\phi(p)$. Furthermore, the elasticity of indexation varies with the industry-specific covariances between input and output prices and the CPI if and only if the supply schedule of workers to the firm is upward sloping $(\epsilon>0)$. When inferences of the alternative wage are held constant, if increases in consumer prices signal an outward shift in the demand curve for labor $\left(r_{1}>0\right.$ or $\left.r_{2}<0\right)$, then the contractual wage increases with prices to compensate for the increasing marginal cost of employment at the firm. On the other hand, if increases in prices signal an inward shift in the demand curve for labor $\left(r_{1}<0\right.$ or $\left.r_{2}>0\right)$, then the contractual real wage rate decreases with the aggregate price level.

While equation (5) generally implies a different elasticity of indexation at each price level, if the variances of opportunity wages and input and output prices are relatively small and the supply of workers to the contract is fairly elastic ( $\epsilon$ is small), then the elasticity of indexation is approximately constant and equal to

$$
\frac{p}{\omega} \omega^{\prime}(p)=c_{1} r_{1}+c_{2} r_{2}+c_{3} r_{3}
$$

where the constants $c_{1}, c_{2}$, and $c_{3}$ are given by

$$
\begin{aligned}
c_{1}= & (\beta+\eta) \frac{\beta(\gamma+\epsilon)+\gamma(1-\delta-\beta) z^{1-\delta}}{\beta[\gamma(\beta-1)+1+\epsilon \beta]}, \\
& +[\delta+\gamma(\beta-1)](1-\delta-\beta) z^{1-\delta}
\end{aligned}
$$

and $z=E(\omega) / \bar{a}$ is a measure of the expected relative contractual wage rate. These expressions follow directly from (5) with the substitutions $\Psi(p)=z^{1-\delta}$ and $\phi(p)=1 .{ }^{24}$

The signs of the coefficients $c_{1}, c_{2}$, and $c_{3}$ can be established from the assumptions that $\epsilon$ is small and that the expected relative wage is close to unity. Under these conditions, $c_{1}$ and $c_{3}$ are positive, while $c_{2}$ is negative. Furthermore, it can be shown that increases in the relative risk aversion of owners translate into increases in the absolute values of $c_{1}$ and $c_{2}$ and decreases in $c_{3}$. If owners are more. risk averse, the stabilization of profits receives greater emphasis in the determination of the optimal wage escalator, and wages are more elastic with respect

${ }^{24}$ Note that (7) implies (6) if $\gamma=\delta=0$, as required by the risk neutrality hypothesis. 
to inferences of input and output prices and less elastic with respect to inferences of the alternative real wage rate. Similar conclusions with respect to changes in the relative risk aversion of workers cannot be established unambiguously. However, for larger values of the relative risk aversion coefficient of workers $(\delta>1.0)$, increases in the risk aversion of workers are associated with reductions in the absolute values of $c_{1}$ and $c_{2}$. Increases in the elasticity of the marginal cost of contractual employment have a similarly ambiguous effect on the coefficients in equation (7). In the risk-neutral case, increases in $\epsilon$, which imply a more inelastic marginal cost schedule, increase the absolute values of $c_{1}$ and $c_{2}$ and decrease the absolute value of the coefficient $c_{3}$. As the supply schedule of additional workers becomes more inelastic, the contract wage becomes more responsive to inferences of shifts in the demand for labor schedule and less responsive to inferences of shifts in the supply schedule itself. These results continue to hold for lower values of the relative risk aversion parameter of workers $(\delta<1.0)$. They are reversed, however, for higher values of the relative risk aversion parameter of workers $(\delta>1.0)$.

Finally, in the absence of risk aversion, the elasticity of indexation is independent of the expected relative wage gap between contractual and alternative employment. If workers are risk averse, however, increases in the expected relative wage tend to decrease the absolute values of the coefficients $c_{1}$ and $c_{2}$ and increase the absolute value of $c_{3}$. In contracts with risk-averse workers and higher relative wages, greater emphasis is placed on stabilizing the differential between the contract wage and the alternative wage, and less emphasis is placed on responding to inferences of labor demand and the profitability of the firm.

\section{Testing the Model of Wage Indexation}

The model of the previous section gives an expression for the elasticity of wage indexation in terms of the parameters of technology, preferences, and the contract environment. Any test of the model against the intercontract distribution of escalation elasticities requires a description of how these parameters vary across contracts. Since firm-specific information is largely unavailable, the testing strategy adopted here is to model escalation elasticities at the three-digit industry level. As it happens, the individual contract data are not inconsistent with the hypothesis that the within-industry distribution of marginal escalation elasticities is uncorrelated with firm-specific factors (see n. 17). In view of this fact, a comparison of the fit of the model to the fit of a simple industry fixed-effects scheme provides a useful 
measure of the success of the model in describing the intercontract distribution of escalation elasticities.

Industry level data are available that permit estimation of several of the components of the escalation formula, including the industryspecific elasticities of labor demand with respect to wages and nonlabor input prices $(-\beta$ and $-\eta$, respectively) and the regression coefficients of output and input price shocks on aggregate price shocks ( $r_{1}$ and $r_{2}$, respectively). I assume that the expected relative wage between contractual and alternative employment $(z)$ is represented by the industry-specific union-nonunion relative wage for unskilled production workers. The remaining parameters of the model, including the elasticities of relative risk aversion $(\delta$ and $\gamma$ ), the elasticity of the opportunity cost of employment schedule $(\epsilon)$, and the regression coefficient of innovations in alternative wages on aggregate price shocks $\left(r_{3}\right)$, are treated as fixed and unknown constants across all industries.

Let $\mathbf{x}_{i}$ be a vector consisting of estimates of the elasticities of labor demand and the union relative wage for the $i$ th three-digit industry$\mathbf{x}_{i}=\left(\beta_{i}, \eta_{i}, z_{i}\right)$-and let $\mathbf{d}$ represent the vector of unknown taste parameters- $\mathbf{d}=(\boldsymbol{\delta}, \boldsymbol{\gamma}, \boldsymbol{\epsilon})$. Assuming that the marginal elasticity measure $e$ represents the desired elasticity of nominal wages with respect to intracontract price increases, equation (7) implies that the logarithm of the marginal elasticity in the contract written by the $j$ th firm in the $i$ th industry in period $t$ is approximately equal to

$$
\log e_{i j t}=c_{1}\left(\mathbf{x}_{i}, \mathbf{d}\right) r_{1 i}+c_{2}\left(\mathbf{x}_{i}, \mathbf{d}\right) r_{2 i}+c_{3}\left(\mathbf{x}_{i}, \mathbf{d}\right) r_{3}+\mu_{i j t},
$$

where $r_{1 i}$ and $r_{2 i}$ are industry-specific estimates of $r_{1}$ and $r_{2} ; c_{1}, c_{2}$, and $c_{3}$ are the coefficients described in equation (7); and $\mu_{i j t}$ has the interpretation of an error term. If $\mu_{i j t}$ contains industry fixed effects, then the parameters $\mathbf{d}$ and $r_{3}$ are unidentifiable and equation (8) is simply a regression on industry dummy variables. On the other hand, if $\mu_{i j t}=$ $\mu_{t}+\nu_{i j t}$, where $\nu_{i j t}$ is homoscedastic and uncorrelated across industries or time periods, then equation (8) implies a nonlinear regression with time period fixed effects. Estimates of equation (8) form the basis for the empirical analysis of indexation provisions in this paper.

Prior to the estimation of equation (8), however, two issues must be addressed. The first of these concerns the estimation of the industryspecific variables on the right-hand side of equation (8). Under the maintained assumption of a Cobb-Douglas production function, industry-specific elasticities of labor demand can be estimated directly from data on the shares of labor and materials costs in the value of industry shipments. ${ }^{25}$ This procedure yields a contract-weighted aver-

\footnotetext{
${ }^{25}$ The share of labor costs in the value of shipments is $(\beta-1)(\beta+\eta)$, while the share of materials costs in the value of shipments is $\eta /(\beta+\eta)$. The value-added data pertain to 1971: data sources are listed in App. C.
} 
age estimate of the elasticity of labor demand of 1.67 and an average estimate of the cross-price elasticity of labor demand with respect to nonlabor input prices of $2.32 .^{26}$

Industry-specific estimates of the union markup of unskilled wage rates $(z)$ can be obtained by comparing wage rates of unskilled laborers in each industry with the average wage rate of nonunion laborers. ${ }^{27}$ This method generates an average estimate of the union relative wage for unskilled nonproduction workers of 1.21 , with larger union differentials in the soft drink, brewery, tobacco, aircraft, and motor vehicle industries and smaller differentials in the textile and furniture industries. These estimated differentials must be interpreted carefully since they do not control for labor force quality by industry. Nonetheless, the general pattern of the differentials is presumably correct.

Industry-specific estimates of the coefficients $r_{1}$ and $r_{2}$ can be obtained from the multivariate time-series representation of the CPI $p_{t}$, the industry selling price $\theta_{t}$, and the industry input price $q_{t}$. In a 1-year contract, $r_{1}$ is just the regression coefficient of unanticipated changes in the annual industry selling price on unanticipated changes in the annual CPI. In principle, $r_{1}$ takes on somewhat different values in the later years of 2- and 3-year contracts. For simplicity, however, differences in contract length are ignored, and all contracts are treated as 1year contracts. ${ }^{28}$

The following regression equations were fit, by industry, to annual observations from 1961 to 1979 on the CPI, the three-digit industry

${ }^{26}$ These elasticities are necessarily larger in absolute value than the constant output elasticities typically estimated in the literature. The Cobb-Douglas functional form implies that the output-constant elasticity of demand for labor with respect to wages is -1 , while the output-constant elasticity of demand for labor with respect to materials prices is zero. Most aggregate studies show that the output-constant elasticity of demand for labor with respect to wages is less than one in absolute value (see Hamermesh 1976).

${ }^{27}$ Microdata estimates of the union relative wage gap by industry are unavailable for Canada. As an alternative I used the following method to obtain crude estimates of the union markup by industry, based on 1971 industry wage data. Assume that the logarithm of the average wage rate of unskilled workers in an industry at a particular location (Toronto, Montreal, or Vancouver, depending on the industry) is a weighted average of the nonunion and union wage rates, where the weight on the union wage is the fraction of unionized workers in the industry. Suppose further that nonunion wage rates for unskilled workers are identical across industries (at a particular location) and equal to 90 percent of the average wage rate across all industries. Then the industryspecific union wage markup is the difference between the log of the average industry wage and the log of the average nonunion wage, divided by the percentage of unionized workers in the industry. The data source for the industry wage rates is listed in App. C.

${ }_{28}$ The individual contract data do not reject this simplifying assumption. When industry fixed effects are held constant, contract length dummy variables are insignificant in a regression equation for the marginal elasticity of indexation. 
selling price (deflated by the CPI), and three-digit intermediate input price (similarly deflated):

$$
\begin{aligned}
\log p_{t}= & a_{1} \log p_{t-1}+a_{2} \log p_{t-2}+\ldots+a_{k} \log p_{t-k}+v_{0 t} \\
\log \theta_{t}= & b_{11} \log \theta_{t-1}+b_{12} \log \theta_{t-2}+b_{21} \log p_{t-1} \\
& +b_{22} \log p_{t-2}+v_{1 t} \\
\log q_{t}= & c_{11} \log q_{t-1}+c_{12} \log q_{t-2}+c_{21} \log p_{t-1} \\
& +c_{22} \log p_{t-2}+v_{2 t}
\end{aligned}
$$

Then, with the estimated residuals from these equations, the coefficients $r_{1}$ and $r_{2}$ were estimated in the auxiliary regressions

$$
\begin{aligned}
& \hat{v}_{1 t}=r_{1} \hat{v}_{0 t}+\xi_{1 t}, \\
& \hat{v}_{2 t}=r_{2} \hat{v}_{0 t}+\xi_{2 t} .
\end{aligned}
$$

Very similar estimates of $r_{1}$ and $r_{2}$ were obtained from a two-step, seemingly unrelated regression model fit to the CPI and the industryspecific prices.

The exclusion restrictions in equations (9) were adopted mainly for parsimony. On the one hand, selective testing revealed no evidence of Granger causality of consumer prices by either industry input prices or industry output prices. Accordingly, the log of the aggregate price level was fit by a second-order autoregression in first differences. On the other hand, the lack of data prior to 1961 dictated a parsimonious representation of the industry input and output prices. Lagged values of input prices were therefore excluded from the output price equations, and vice versa. A 2-year lag specification in equations (9b) and (9c) generally fit the industry price data well and more or less eliminated serial correlation in the forecast errors. ${ }^{29}$

The estimates of $r_{1}$ average .27 across the 44 three-digit industries. Tobacco products, metal stamping, aircraft, truck assembly, railroad equipment, and communications equipment industries yield large negative estimates of $r_{1}$ (between -.90 and -.30 ), while meat packing, bakery products, textile, woodworking, pulp and paper, iron and steel, and agricultural equipment industries yield large positive estimates of $r_{1}$ (between .50 and 3.0). Across industries, the pattern of $r_{2}$ is similar to that of $r_{1}$. In fact, the contract-weighted correlation of the estimates of $r_{1}$ and $r_{2}$ is .76. As one might expect, industries with positive correlations between output selling prices and aggregate price shocks tend to be those with positive correlations between input

${ }^{29}$ Unfortunately, the sample period includes the 1973-74 episode of dramatic increases in raw materials prices. To the extent that the pattern of these increases was extraordinary, data from 1973-74 represent outliers that should be discounted in estimation. Some experimentation revealed that the estimates of $r_{1}$ and $r_{2}$ were fairly sensitive to inclusion or exclusion of the 1973-74 data. 
prices and aggregate price shocks. One exception is the soft drink industry, in which selling price shocks are negatively correlated with consumer prices while input price shocks are positively correlated with the CPI.

The industry-specific elasticities of labor demand, the unionnonunion relative wage, and the regression coefficients $r_{1}$ and $r_{2}$ are all measured with error. It is well known that measurement error in the exogenous variables of a regression equation leads to inconsistent parameter estimates and nullifies standard inference procedures. Given the shortcomings of the data used to estimate the industry variables, therefore, the parameter estimates and inferences obtained from the cross-sectional estimation of equation (8) must be interpreted cautiously.

A second issue in the estimation of equation (8) is selection bias. A large fraction of union contracts contain no escalation provisions. ${ }^{30}$ One interpretation of a fixed wage contract is as an indexed contract in which the optimal elasticity of nominal wages with respect to aggregate prices is approximately zero. According to this interpretation, estimation of equation (8) on a sample of indexed contracts leads to biased parameter estimates since the regression function and the error term in (8) are correlated, given that the contract is indexed (i.e., given that the optimal elasticity of nominal wages is greater than zero). If information on nonindexed contracts was available, equation (8) could be corrected for selection bias in the manner suggested by Heckman (1976). Since data on nonindexed contracts are not readily available, however, such a correction is beyond the scope of the present analysis.

On the other hand, the decision to index is based on several factors besides the deviation of the optimal elasticity of indexation from zero. Other things equal, indexation is more valuable when there is greater variance in the aggregate price level and in industries where the conditional forecast variances of market-specific prices, given the aggregate price level, are smaller. ${ }^{31}$ To the extent that the indexation deci-

\footnotetext{
${ }^{30}$ In 1982, e.g., only 22 percent of the major agreements signed in Canada included indexation clauses. In the same year, 57 percent of workers covered by major contracts in the United States had index-linked wages.

${ }^{31}$ The relationship between the variance of the aggregate price level and the indexation decision is described by Ehrenberg, Danziger, and San (1983). As an empirical matter, most of the changes over time in the proportion of indexed contracts seem to be correlated with aggregate price level uncertainty. For example, in 1958 the proportion of workers in major union contracts in the United States covered by indexation provisions stood at 50 percent. This fraction fell steadily through the early 1960 s, reaching 20 percent in 1966 . Then, in the late 1960 s and early 1970 s, there was a sharp resurgence in indexed contracts (see Douty 1975, p. 12, table 1). Coverage by escalation provisions reached 60 percent in 1978 and has fallen only slightly since then (see Davis 1983).
} 
sion is influenced by factors other than the magnitude of the optimal elasticity of indexation, selection bias in the estimation of equation (8) over the subset of indexed contracts is lessened.

Before I turn to estimates of equation (8), it is useful to consider estimates of some simple linearized versions of the model. If interindustry differences in the elasticities of labor demand and the gap between contractual and alternative wages are ignored, then equation (8) is just a linear regression on the parameters $r_{1}$ and $r_{2}$. Furthermore, the regression coefficients are interpretable as estimates of the coefficients $c_{1}$ and $c_{2}$ in equation (7), and the constant term in the regression is interpretable as an estimate of $c_{3} r_{3}$. The results of this regression are recorded in column 1 of table 1 . The estimated coefficients are very precisely determined and remarkably consistent with the theoretical model. In particular, the estimated regression coefficient of $r_{1}$ is positive, the estimated regression coefficient of $r_{2}$ is negative, and their ratio, which is an estimate of $-(\beta+\eta) / \eta$, is of the correct order of magnitude. ${ }^{32}$ For the risk-neutral specification of firms' and workers' preferences, these estimates imply an estimate of the inverse elasticity of labor supply $(\epsilon)$ of about .03 (with demand elasticities set at their industry average values). Assuming that the coefficient $c_{3}$ is positive, these estimates also imply that the correlation of aggregate price shocks and innovations in alternative real wages is negative.

The second column of table 1 extends the list of regressors to include the industry-specific elasticities of labor demand and the industry-specific relative wage. While higher union-nonunion relative wages apparently reduce the elasticity of indexation, neither of the demand elasticities adds significantly to the regression. On the other hand, equation (8) is highly nonlinear in the elasticities of labor demand, and their impact on the marginal elasticity of indexation may not be adequately captured by a simple linear regression.

The third and fourth columns of table 1 report the same regressions as the first two columns, with fixed effects for the signing dates of the contracts included as exogenous variables. While the signing date fixed effects improve the fit of the regressions, they have only a minor impact on the estimated coefficients of the industry variables.

Table 2 presents nonlinear least-squares estimates of equation (8), utilizing the functional forms for $c_{1}, c_{2}$, and $c_{3}$ recorded in equation (7). The first column of the table contains estimates of equation (8) under the assumption that the marginal cost of contractual employ-

${ }^{32}$ The contract-weighted average value of $\eta /(\beta+\eta)$ is .53. For the estimates in col. 1 of table 1 , the restriction that the regression coefficient of $r_{2}$ is -.53 times the regression coefficient of $r_{1}$ yields a $t$-ratio of 2.46 . 
TABLE 1

Least-Squares Regressions for the Logarithm of the Marginal Elasticity

\begin{tabular}{|c|c|c|c|c|}
\hline \multirow[b]{3}{*}{ Estimated Coefficient } & \multicolumn{4}{|c|}{ Signing Date Fixed Effects } \\
\hline & \multicolumn{2}{|c|}{ Excluded } & \multicolumn{2}{|c|}{ Included } \\
\hline & (1) & $(2)$ & (3) & (4) \\
\hline 1. Constant & $\begin{array}{r}-.229 \\
(.013)\end{array}$ & $\begin{array}{l}.186 \\
(.220)\end{array}$ & $\begin{array}{r}-.190 \\
(.048)\end{array}$ & $\begin{array}{l}-.036 \\
(.229)\end{array}$ \\
\hline $\begin{array}{l}\text { 2. Regression coefficient of } \\
\text { industry output price on } \\
\text { CPI }\left(r_{1}\right)\end{array}$ & $\begin{array}{l}.103 \\
(.021)\end{array}$ & $\begin{array}{l}.086 \\
(.024)\end{array}$ & $\begin{array}{l}.086 \\
(.019)\end{array}$ & $\begin{array}{l}.064 \\
(.022)\end{array}$ \\
\hline $\begin{array}{l}\text { 3. Regression coefficient of } \\
\text { industry input price on } \\
\text { CPI }\left(r_{2}\right)\end{array}$ & $\begin{array}{r}-.079 \\
(.016)\end{array}$ & $\begin{array}{c}-.063 \\
(.018)\end{array}$ & $\begin{array}{r}-.077 \\
(.014)\end{array}$ & $\begin{array}{c}-.060 \\
(.016)\end{array}$ \\
\hline $\begin{array}{l}\text { 4. Wage elasticity of } \\
\text { labor demand }(\beta)\end{array}$ & $\cdots$ & $\begin{array}{r}-.042 \\
(.057)\end{array}$ & $\cdots$ & $\begin{aligned}-.024 \\
(.052)\end{aligned}$ \\
\hline $\begin{array}{l}\text { 5. Input price elasticity } \\
\text { of labor demand }(\eta)\end{array}$ & $\cdots$ & $\begin{array}{l}.004 \\
(.008)\end{array}$ & $\cdots$ & $\begin{array}{l}.003 \\
(.008)\end{array}$ \\
\hline $\begin{array}{l}\text { 6. Industry relative union- } \\
\text { nonunion wage }\end{array}$ & $\cdots$ & $\begin{array}{r}-.277 \\
(.149)\end{array}$ & $\cdots$ & $\begin{aligned}-.304 \\
(.136)\end{aligned}$ \\
\hline 7. Standard error & .1745 & .1721 & .1547 & .1542 \\
\hline 8. $R^{2}$ & .13 & .15 & .32 & .34 \\
\hline $\begin{array}{l}\text { 9. F-test for signing } \\
\text { date effects* (mar- } \\
\text { ginal significance) }\end{array}$ & $\cdots$ & $\cdots$ & $\begin{array}{l}6.08 \\
(.000)\end{array}$ & $\begin{array}{l}6.03 \\
(.000)\end{array}$ \\
\hline
\end{tabular}

Note. - The mean of the dependent variable is -.224 with a sample standard deviation of 188 . The data consist of marginal elasticities from 189 contracts drawn from 44 three-digit industries in the Canadian manufacturing sector. Estimated standard errors are in parentheses.

* $F$-statistic for the null hypothesis of no signing date effects.

ment is constant at the alternative wage, that is, that $\epsilon=0$ in the union utility function (3). The parameter estimates imply that workers are substantially more risk averse than owners, although the assumption that owners are risk neutral is rejected by a conventional test. ${ }^{33}$ The estimated coefficient of relative risk aversion of workers is 2.45 - very close to the estimate obtained by Farber (1978) in modeling wage determination in the coal industry. The estimate of the parameter $r_{3}$ is -.40 , implying that a 1 percent innovation in the consumer price index is associated with a 0.4 percent reduction in alternative real wages available to employees in union contracts. In the aggregate Canadian labor market, the regression coefficient of annual real wage shocks on concurrent price level shocks is about $-.65 .{ }^{34}$ Thus the fact that average elasticities of indexation are some-

${ }^{33}$ In the presence of measurement error in the industry variables, however, conventional significance levels may be inappropriate.

3.4 This estimate is obtained from the correlation of the residuals from a second-order vector autoregressive representation of the logarithms of annual real average hourly earnings in manufacturing and the CPI. 
TABLE 2

Nonlinear Least-SQuares Estimates of Equation (8)

\begin{tabular}{|c|c|c|c|}
\hline & \multicolumn{3}{|c|}{$\begin{array}{l}\text { DEPENDENT Variable: Log Of THE } \\
\text { Marginal Elasticity OF INDEXation* }\end{array}$} \\
\hline & (1) & $(2)$ & $(3)$ \\
\hline \multicolumn{4}{|l|}{ Parameter estimates: } \\
\hline \multirow{2}{*}{$\begin{array}{l}\text { 1. Relative risk } \\
\text { aversion of workers }(\delta)\end{array}$} & 2.45 & .00 & 2.35 \\
\hline & $(.70)$ & & $(.70)$ \\
\hline \multirow{2}{*}{$\begin{array}{l}\text { 2. Relative risk } \\
\text { aversion of owners }(\gamma)\end{array}$} & .148 & .00 & .232 \\
\hline & $(.042)$ & $\ldots$ & $(.101)$ \\
\hline \multirow{2}{*}{$\begin{array}{l}\text { 3. Elasticity of opportunity } \\
\text { cost of employment }(\epsilon)\end{array}$} & .00 & .029 & .036 \\
\hline & $\ldots$ & $(.002)$ & $(.040)$ \\
\hline \multirow{2}{*}{$\begin{array}{l}\text { 4. Regression coefficient } \\
\text { of alternative wage on CPI } \\
\left(r_{3}\right)\end{array}$} & -.403 & -.246 & -.40 \\
\hline & $(.024)$ & $(.014)$ & $(.02)$ \\
\hline \multicolumn{4}{|l|}{ Average value of: } \\
\hline 5. $c_{1}$ & .092 & .110 & .085 \\
\hline 6. $c_{2}$ & -.051 & -.063 & -.047 \\
\hline 7. $c_{3}$ & .585 & .954 & .600 \\
\hline 8. Standard error & .1722 & .1775 & .1718 \\
\hline 9. $R^{2}$ & .15 & .10 & .16 \\
\hline \multirow{2}{*}{$\begin{array}{l}\text { 10. } \chi^{2} \text { test statistic }{ }^{\dagger} \\
\text { (marginal significance) }\end{array}$} & 64.9 & 70.7 & 64.5 \\
\hline & $(.010)$ & $(.004)$ & $(.008)$ \\
\hline
\end{tabular}

thing less than unity is consistent with the short-run fixity of nominal wages rates elsewhere in the economy.

Rows 8-10 of table 2 contain measures of the goodness of fit of the various specifications of equation (8). The risk-averse version of the model in the first column of the table explains about 15 percent of the intercontract dispersion in elasticities of indexation. Relative to a benchmark regression on industry fixed effects, however, it does somewhat better. In fact, the test statistic against this general specification (in row 10 of the table) has a marginal significance level of 1 percent. In view of the parsimonious nature of the model, this is not an unreasonable standard of performance.

The second column of table 2 presents estimates of a risk-neutral specification of equation (8). In this formulation, the only parameters are $\epsilon$, the inverse elasticity of labor supply to the contract, and the coefficient $r_{3}$. As the $R^{2}$ statistics indicate, the risk-neutral specification fits less well than the risk-averse version of the model. This should not be surprising, however, given that the risk-neutral specification excludes the relative wage variable $z$ from the elasticity formula and given the fact that in linear form, at least, higher relative wages have a significantly negative impact on the elasticity of indexa- 
tion. The parameter estimates imply that the supply schedule of workers to the contract is fairly elastic although not flat. Furthermore, the estimate of $r_{3}$ is negative although somewhat smaller in absolute value than the estimate obtained under the assumption of risk aversion.

Some further insight into the differences between model specifications is provided by the average values of the coefficients $c_{1}, c_{2}$, and $c_{3}$, recorded in rows $5-7$ of the table. The average values of $c_{1}$ and $c_{2}$ are similar between specifications. However, under risk neutrality, the average value of the coefficient $c_{3}$ is .95 while, under risk aversion, the average value is .59 . Since, roughly speaking, the estimate of $r_{3}$ is selected so that the average value of $c_{3} r_{3}$ fits the mean of the dependent variable, this difference in estimates of $r_{3}$ between specifications is understandable.

The final column in table 2 reports estimates of a combined model that includes both the risk-averse and risk-neutral specifications of the union utility function as special cases. The estimate of the risk aversion parameter for workers is essentially the same as that in column 1 of the table. Allowing for increasing marginal costs of employment, however, the estimate of owners' relative risk aversion is larger than in the pure risk specification and less precise. The estimate of the inverse elasticity of supply is .04, although this estimate is not different from zero at conventional significance levels. Generally speaking, the combined model represents only a minor improvement over the risk-averse specification, and there is no strong basis to choose between them.

These same conclusions emerge from estimates of equation (8) when year-specific fixed effects are included in the regression equation. ${ }^{35}$ Results for this procedure are summarized in table 3 . The addition of a set of fixed effects for the signing dates of the contracts has very little impact on any of the estimated parameters. Furthermore, the relative performance of the three alternative specifications of union preferences is the same in the presence or absence of signing date effects, and the test statistics comparing the explanatory power of the model to a general industry fixed-effects scheme are virtually identical in tables 2 and 3.

Test statistics for the joint significance of the year effects are presented in row 11 of table 3 . Across all three specifications of union preferences there is evidence of time-varying elasticities of indexa-

\footnotetext{
${ }^{35}$ Since eq. (8) does not include an unrestricted intercept, the parameter estimates are not invariant to the choice of a basis year from which to measure the year effects. Arbitrarily, 1971 was selected as a basis year. The mean elasticity among contracts signed in 1971 is very close to the mean elasticity over all years. Alternative choices for the basis year mainly affect the estimate of $r_{3}$.
} 
TABLE 3

Nonlinear Least-Squares Estimates of Equation (8) Including Year Fixed EFFECTS

\begin{tabular}{|c|c|c|c|}
\hline & \multicolumn{3}{|c|}{$\begin{array}{l}\text { DEPENDENT Variable: LoG OF THE } \\
\text { MaRGINAL ElaSticity OF INDEXation }\end{array}$} \\
\hline & (1) & $(2)$ & (3) \\
\hline \multicolumn{4}{|l|}{ Parameter estimates: } \\
\hline $\begin{array}{l}\text { 1. Relative risk } \\
\text { aversion of workers }(\delta)\end{array}$ & $\begin{array}{l}2.84 \\
(.78)\end{array}$ & $\begin{array}{l}.00 \\
\ldots .\end{array}$ & $\begin{array}{l}2.74 \\
(.78)\end{array}$ \\
\hline $\begin{array}{l}\text { 2. Relative risk } \\
\text { aversion of owners }(\gamma)\end{array}$ & $\begin{array}{l}.128 \\
(.042)\end{array}$ & $\begin{array}{l}.00 \\
\ldots\end{array}$ & $\begin{array}{l}.234 \\
(.097)\end{array}$ \\
\hline $\begin{array}{l}\text { 3. Elasticity of opportunity } \\
\text { cost of employment }(\epsilon)\end{array}$ & .00 & $\begin{array}{l}.023 \\
(.007)\end{array}$ & $\begin{array}{l}.053 \\
(.044)\end{array}$ \\
\hline $\begin{array}{l}\text { 4. Regression coefficient of } \\
\text { alternative wage on CPI } \\
\left(r_{3}\right)\end{array}$ & $\begin{array}{c}-.361 \\
(.048)\end{array}$ & $\begin{aligned}-.225 \\
(.033)\end{aligned}$ & $\begin{aligned}-.355 \\
(.046)\end{aligned}$ \\
\hline \multicolumn{4}{|l|}{ Average value of: } \\
\hline 5. $c_{1}$ & .069 & .087 & .060 \\
\hline 6. $c_{2}$ & -.039 & -.051 & -.032 \\
\hline 7. $c_{3}$ & .579 & .963 & .593 \\
\hline 8. Standard error & .1553 & .1606 & .1548 \\
\hline 9. $R^{2}$ & .31 & .26 & .32 \\
\hline $\begin{array}{l}\text { 10. } \chi^{2} \text { test statistic } \\
\text { (marginal significance) }\end{array}$ & $\begin{array}{l}63.7 \\
(.013)\end{array}$ & $\begin{array}{l}69.9 \\
(.005)\end{array}$ & $\begin{array}{l}63.0 \\
(.011)\end{array}$ \\
\hline $\begin{array}{l}\text { 11. } \chi^{2} \text { test for year effects* } \\
\text { (marginal significance) }\end{array}$ & $\begin{array}{l}19.4 \\
(.013)\end{array}$ & $\begin{array}{l}19.0 \\
(.015)\end{array}$ & $\begin{array}{l}19.7 \\
(.011)\end{array}$ \\
\hline
\end{tabular}

Note. - See notes to table 2 . The regressions include fixed effects for contracts signed in each year from 1967 to 1975. Estimated standard errors are in parentheses.

* Difference in the maximized log likelihood, including and excluding signing date fixed effects.

tion. The estimated year effects indicate a trend toward higher marginal elasticities over the $1968-75$ period, although the trend is irregular. ${ }^{36}$

One explanation for this trend is an increase in the variability of the aggregate price level over the sample period. When the variances of real price movements are held constant, increases in the variance of the consumer price index force the coefficients $r_{1}, r_{2}$, and $r_{3}$ toward zero and force the elasticity of indexation toward unity. Many simple time-series models indicate a higher residual variance in the aggregate price level in the mid-1970s relative to the previous decade. ${ }^{37}$ Since most marginal elasticities are less than one, this implies a trend toward higher marginal elasticities over the sample period. A careful

${ }^{36}$ The mean elasticities of indexation by signing date of the contract are 1967, .65 (3 contracts); $1968, .70$ (7 contracts); $1969, .75$ (10 contracts); 1970, .77 (14 contracts); $1971, .83$ (27 contracts); 1972, .72 (11 contracts); 1973, .73 (22 contracts); 1974, .87 (62 contracts); 1975, .87 (33 contracts).

${ }^{37}$ Riddell and Smith (1982) fit a time-varying autoregressive moving average model to the Canadian CPI and find increasing residual variances in the 1970s. 
investigation of this hypothesis, however, requires time-varying estimates of the covariances between industry and aggregate prices and is beyond the scope of this paper.

A comparison of the nonlinear regressions in tables 2 and 3 with the simple linear regressions in table 1 reveals that the latter fit about as well as the former when the industry-specific demand elasticities and relative wage variables are included in the linear regressions. On the other hand, the results in table 1 suggest that the industry-specific labor demand elasticities are insignificant determinants of the marginal elasticity of indexation. While this may reflect the nonlinearity of the true relationship between escalation elasticities and demand elasticities, an alternative explanation is that measurement error in the estimated demand elasticities is large relative to the cross-sectional variation in these variables. In the context of equation (8), a simple test of this hypothesis is obtained by fixing the elasticities of labor demand across industries and then reestimating the equation, using only the interindustry variation in the relative wage and the parameters $r_{1}$ and $r_{2}$ to identify the parameters of the model. Results for this procedure, when the demand elasticities are set equal to their average values across all industries, are displayed in table 4 . For all three

\section{TABLE 4}

Nonlinear Least-Squares Estimates of Equation (8):

Elasticities of Labor Demand Fixed

\begin{tabular}{|c|c|c|c|}
\hline & \multicolumn{3}{|c|}{$\begin{array}{l}\text { DePENDENT Variable: LoG of the } \\
\text { Marginal Elasticity OF INDEXation }\end{array}$} \\
\hline & (1) & $(2)$ & (3) \\
\hline \multicolumn{4}{|l|}{ Parameter estimates: } \\
\hline 1. Relative risk & 1.94 & .00 & 1.93 \\
\hline aversion of workers $(\delta)$ & $(.67)$ & $\ldots$ & $(.68)$ \\
\hline 2. Relative risk & .110 & .00 & .138 \\
\hline aversion of owners $(\gamma)$ & $(.038)$ & $\ldots$ & $(.086)$ \\
\hline $\begin{array}{l}\text { 3. Elasticity of opportunity } \\
\text { cost of employment }(\epsilon)\end{array}$ & $\begin{array}{l}.00 \\
\ldots\end{array}$ & $\begin{array}{c}.028 \\
(.006)\end{array}$ & $\begin{array}{l}.008 \\
(.024)\end{array}$ \\
\hline $\begin{array}{l}\text { 4. Regression coefficient } \\
\text { of alternative wage on CPI } \\
\left(r_{3}\right)\end{array}$ & $\begin{array}{r}-.387 \\
(.029)\end{array}$ & $\begin{aligned}-.246 \\
(.014)\end{aligned}$ & $\begin{array}{r}-.388 \\
(.030)\end{array}$ \\
\hline \multicolumn{4}{|l|}{ Average value of: } \\
\hline 5. $c_{1}$ & .085 & .106 & .083 \\
\hline 6. $c_{2}$ & -.049 & -.061 & -.048 \\
\hline 7. $c_{3}$ & .614 & .956 & .618 \\
\hline 8. Standard error & .1730 & .1761 & .1730 \\
\hline 9. $R^{2}$ & .15 & .11 & .15 \\
\hline $\begin{array}{l}\text { 10. } \chi^{2} \text { test statistic } \\
\text { (marginal significance) }\end{array}$ & $\begin{array}{l}65.8 \\
(.008)\end{array}$ & $\begin{array}{l}69.1 \\
(.005)\end{array}$ & $\begin{array}{l}65.8 \\
(.006)\end{array}$ \\
\hline
\end{tabular}

Note.-See notes to table 2. The estimates in this table were obtained by setting the elasticities of labor demand in each industry to their average values across all industries. Estimated standard errors in parentheses. 
specifications of union preferences, the parameter estimates and the fit of the model are similar to the corresponding results in table 2 . As it happens, the estimates in table 4 are highly robust to the values of the elasticities of labor demand inserted in equation (8), and the fit of the model is largely unaffected by alternative choices for these two parameters. ${ }^{38}$

Several conclusions emerge from the empirical analysis in tables 14. First, the basic insight of the theoretical model is confirmed. Marginal escalation elasticities are higher in industries with higher correlations between output price shocks and aggregate price shocks and lower in industries with higher correlations between input price shocks and aggregate price shocks. Second, the fact that escalation elasticities average something less than unity is attributed to the behavior of wage rates outside the contracts. In this regard the evidence from the indexed contract sample is consistent with the observed relationship between aggregate real wages and consumer prices. Third, although the model predicts that firm-specific elasticities of labor demand are important determinants of the elasticity of indexation, there is no strong evidence for this hypothesis in the contract data. On the other hand, the estimated elasticities of labor demand may simply contain too much measurement error to provide a meaningful test. Fortunately, the performance of the model and the parameter estimates are fairly robust to alternative assumptions on the cross-sectional pattern of these elasticities.

The contract data do, however, provide evidence of a negative correlation between relative contractual wage rates and the marginal elasticity of indexation. In the context of the theoretical model, this is interpreted as evidence of risk aversion on the part of union members. If employees are risk averse, the model suggests that the elasticity of indexation is closer to the elasticity of alternative wages with respect to aggregate price shocks, the larger is the gap between contractual and alternative wages. Since alternative wages respond negatively to upward movements in aggregate prices, the implied correlation of marginal escalation elasticities and relative wages is negative. ${ }^{39}$

\footnotetext{
${ }^{38}$ For example, when the wage elasticity of labor demand is set at -.70 and the input price elasticity of labor demand is set at -.60 , the parameter estimates and their estimated standard errors are as follows: for the pure risk specification (col. 1 in tables $2-4) \delta=2.49(.63), \gamma=.200(.061), r_{3}=.745$ (.063), standard error of the regression $=.1746$; for the risk-neutral specification (col. 2 in tables $2-4) \epsilon=.0741(.018), r_{3}=$ $-.249(.015)$, standard error of the regression $=.1786$; for the combined specification (col. 3 in tables $2-4) \delta=2.47(.66), \gamma=.608(.223), \epsilon=.566(.331), r_{3}=-.677(.088)$, standard error of the regression $=.1733$.

${ }^{39}$ An alternative explanation for the negative correlation between industry relative wages and industry escalation elasticities is that contract negotiators tend to mimic indexation provisions in other recent contracts. If low-wage industries adopt the same indexed wage increase per point increase in the CPI as other industries, they induce a
} 
Finally, although industry-specific union-nonunion wages and industry-specific correlations between input and output prices and the CPI explain only a moderate share of the dispersion in escalation elasticities across contracts, the relationship between observed escalation elasticities and the industry variables is remarkably consistent with the simple model of union preferences and firm behavior developed in this paper. Overall, the data seem to favor a model of coinsurance between workers and owners in which workers receive some protection from shocks to alternative wages at the same time as owners receive some protection from shocks to profits. The data also show a trend toward higher marginal elasticities over the sample period. Whether or not this trend is consistent with the model, however, remains unanswered.

\section{Summary and Conclusions}

This paper develops and tests a model of indexation in long-term labor contracts. On the basis of observed contracts, a measure of the elasticity of indexation is derived and its pattern across a sample of indexed contracts is presented. Of particular interest are two characteristics of measured elasticities of indexation: their wide dispersion and their large industry-specific component of variance.

In Section II of the paper a simple one-period contract model is developed under the assumption that the contractual wage rate is linked to the aggregate price level. The implications of several alternative specifications of workers' preferences are derived for the elasticity of contractual wages with respect to consumer prices. The elasticity of indexation is shown to depend on the parameters of the firm's production function, the parameters of workers' and owners' utility functions, and the relationship between firm-specific prices and the aggregate price index.

The model does not explain a number of interesting and important aspects of cost-of-living allowance clauses in collective bargaining agreements. First, no attempt is made to justify index-linking solely to consumer prices. Second, the model gives no insights into the preponderance of indexation clauses that yield the same absolute wage increases to all workers in a given contract. Finally, the model does not

\footnotetext{
negative correlation between industry wage rates and marginal escalation elasticities. I tested this hypothesis by regressing the logarithm of the cents-per-point wage increase awarded by the escalator (the parameter $\alpha$ in eq. [1]), multiplied by the price index at the signing date of the contract, on the log of the wage rate at the signing date of the contract and the industry-specific variables. The estimated coefficient on the contract wage was .92 with a standard error of .04 , implying only weak evidence against the marginal elasticity specification of eq. (8).
} 
explain the use of both noncontingent deferred increases and indexlinking provisions in escalated contracts.

In Section III the model is tested as a description of the distribution of escalation elasticities across contracts. Estimates are provided for some of the variables in the model by three-digit industry, and the remainder of the variables are treated as unknown parameters. The estimation results reveal a significant role for the industry variables in explaining the intercontract distribution of escalation elasticities, although a hypothesized relation between industry-specific elasticities of labor demand and the indexation formulas is not confirmed. The parameter estimates imply that union preferences can be represented by a simple expected utility of employment function. They also imply that firms display some aversion toward the risks of profit variability. The estimated relative risk aversion of workers is about 2.5 , while the estimated relative risk aversion of owners of firms is about 10 .

In spite of its simplicity, the model enjoys a reasonable degree of success in describing the interindustry pattern of escalation elasticities. The contract data provide strong support for the basic premise of the model: that the response of index-linked wages to aggregate price increases depends on the information that aggregate prices convey for the market-specific prices of interest to the bargaining parties.

\section{Appendix A}

This Appendix presents an expression for $E\left(x^{a} \mid y\right)$ when $x$ and $y$ have a joint lognormal distribution.

Suppose $\log x$ and $\log y$ are jointly normally distributed with means $\log \bar{x}$ and $\log \bar{y}$, respectively, variances $\sigma_{x}^{2}$ and $\sigma_{y}^{2}$, respectively, and covariance $\rho \sigma_{x} \sigma_{y}$. Given $y, \log x$ is normally distributed with mean $\log \bar{x}+\rho\left(\sigma_{x} / \sigma_{y}\right)(\log y-\log \bar{y})$, and the variance $\sigma_{x}^{2}\left(1-\rho^{2}\right)$ or, equivalently, $(x / \bar{x})$ is lognormally distributed, with the mean of $\log (x / \bar{x})$ equal to $\rho\left(\sigma_{x} / \sigma_{y}\right) \log (y / \bar{y})$ and the variance of $\log (x / \bar{x})$ equal to $\sigma_{x}^{2}\left(1-\rho^{2}\right)$. Since

$$
E\left(x^{a} \mid y\right)=\bar{x}^{a} E\left[\left(\frac{x}{\bar{x}}\right)^{a} \mid y\right]
$$

it is sufficient to find $E\left(z^{a}\right)$ for $z \operatorname{lognormally}$ distributed with mean $\log z=\mu$ and variance $\log z=\sigma^{2}$.

Using the expression for the lognormal density function, we get

$$
\begin{aligned}
E\left(z^{a}\right) & =\int_{0}^{\infty} z^{a} \frac{1}{z} \frac{1}{\sqrt{2 \pi}} \frac{1}{\sigma} \exp \left[-1 / 2\left(\frac{\log z-\mu}{\sigma}\right)^{2}\right] d z \\
& =\int_{-\infty}^{\infty} e^{a w} \frac{1}{\sqrt{2 \pi}} \frac{1}{\sigma} \exp \left[-1 / 2\left(\frac{w-\mu}{\sigma}\right)^{2}\right] d w,
\end{aligned}
$$


performing the change of variables $w=\log z$. The latter expression is just the expression for the moment-generating function of a normally distributed variable. Therefore,

$$
E\left(z^{a}\right)=\exp \left(a \mu+1 / 2 a^{2} \sigma^{2}\right),
$$

and substituting $z=x / \bar{x}, \mu=\rho\left(\sigma_{x} / \sigma_{y}\right) \log (y / \bar{y})$, and $\sigma^{2}=\sigma_{x}^{2}\left(1-\rho^{2}\right)$, we get

$$
E\left(x^{a} \mid y\right)=\bar{x}^{a} \exp \left[a \rho \frac{\sigma_{x}}{\sigma_{y}} \log \left(\frac{y}{\bar{y}}\right)+1 / 2 a^{2} \sigma_{x}^{2}\left(1-\rho^{2}\right)\right] .
$$

\section{Appendix B}

This Appendix presents a derivation of equation (5) in the text. The first step is to evaluate the first-order condition (4). From (3),

$$
\begin{aligned}
\mu_{1} \equiv \frac{\partial U}{\partial \omega}+\frac{\partial U}{\partial L} \frac{\partial L}{\partial \omega}= & L u^{\prime}(\omega)+\left[u(\omega)-u(a) \frac{1}{1+\epsilon}\left(\frac{L}{L_{0}}\right)^{\epsilon}\right] \frac{\partial L}{\partial \omega} \\
& -u(a) \frac{\epsilon}{1+\epsilon}\left(\frac{L}{L_{0}}\right)^{\epsilon} \frac{\partial L}{\partial \omega} .
\end{aligned}
$$

Substituting $\partial L / \partial \omega=-\beta(L / \omega)$, we get

$$
\begin{aligned}
\mu_{1}= & L\left\{u^{\prime}(\omega)-\frac{\beta}{\omega}\left[u(\omega)-u(a)\left(\frac{L}{L_{0}}\right)^{\epsilon}\right]\right\} \\
= & \left(\frac{1-\delta-\beta}{1-\delta}\right) \theta^{\beta+\eta} \omega^{-\beta-\delta} q^{-\eta} \\
& +\frac{\beta}{1-\delta} L_{0}^{-\epsilon} \theta^{(\beta+\eta)(1+\epsilon)} \omega^{-1-\beta(1+\epsilon)} q^{-\eta(1+\epsilon)} a^{1-\delta},
\end{aligned}
$$

using $L=\theta^{\beta+\eta} \omega^{-\beta} q^{-\eta}$, and $u(\omega)=[1 /(1-\delta)] \omega^{1-\delta}$. From the envelope property of the profit function, $\partial \pi / \partial \omega=-L$, and therefore

$$
\mu_{2} \equiv \nu^{\prime}(\pi) \frac{\partial \pi}{\partial \omega}=-\left(\frac{1}{\beta-1}\right)^{-\gamma} \omega^{-\beta-\gamma(1-\beta)} \theta^{(\beta+\eta)(1-\gamma)} q^{-\eta(1-\gamma)} .
$$

The first-order condition is

$$
E\left(\mu_{2}+\lambda \mu_{1} \mid p\right)=0
$$

which implies

$$
\begin{gathered}
\frac{1-\delta-\beta}{1-\delta} \bar{\theta}^{\beta+\eta} \bar{q}^{-\eta} \omega^{-\beta-\delta} E\left[\left(\frac{\theta}{\bar{\theta}}\right)^{\beta+\eta}\left(\frac{q}{\bar{q}}\right)^{-\eta} \mid p\right] \\
+\frac{\beta}{1-\delta} \omega^{-1-\beta-\epsilon \beta} L_{0}^{-\epsilon} \bar{a}^{1-\delta} \bar{\theta}^{(\beta+\eta)(1+\epsilon)} \bar{q}^{-\eta(1+\epsilon)} \\
\quad \times E\left[\left(\frac{\theta}{\bar{\theta}}\right)^{(\beta+\eta)(1+\epsilon)}\left(\frac{q}{\bar{q}}\right)^{-\eta(1-\epsilon)}\left(\frac{a}{\bar{a}}\right)^{1-\delta} \mid p\right] \\
=K \omega^{-\beta-\gamma(1-\beta)} \bar{\theta}^{(\beta+\eta)(1-\gamma)} \bar{q}^{-\eta(1-\gamma)} E\left[\left(\frac{\theta}{\bar{\theta}}\right)^{(\beta+\eta)(1-\gamma)}\left(\frac{q}{\bar{q}}\right)^{-\eta(1-\gamma)} \mid p\right],
\end{gathered}
$$


where $K$ is a constant. The expectations can be evaluated using the formula in Appendix A, assuming that the conditional distributions of $(\theta, r, a)$, given $p$, are independent. Let

$$
\begin{aligned}
& t_{1}=(\beta+\eta) r_{1}-\eta r_{2}, t_{2}=(1-\delta) r_{3}, \\
& s_{1}=1 / 2(\beta-\eta)^{2} \sigma_{1}^{2}+1 / 2 \eta^{2} \sigma_{2}^{2}, s_{2}=1 / 2(1-\delta)^{2} \sigma_{3}^{2} .
\end{aligned}
$$

Then (Bl) can be written as

$$
\begin{gathered}
\frac{1-\delta-\beta}{1-\delta} \omega^{-\delta} \exp \left[t_{1} \log \left(\frac{p}{\bar{p}}\right)+s_{1}\right] \\
+\frac{\beta}{1-\delta} \omega^{-1-\epsilon \beta} L_{0}^{-\epsilon} \bar{a}^{1-\delta} \bar{\theta}^{(\beta+\eta) \epsilon} \bar{q}^{-\eta \epsilon} \\
\times \exp \left\{\left[(1+\epsilon) t_{1}+t_{2}\right] \log \left(\frac{p}{\bar{p}}\right)+(1+\epsilon)^{2} s_{1}+s_{2}\right\} \\
=K \omega^{-\gamma(1-\beta)} \bar{\theta}^{-(\beta+\eta) \gamma} \bar{q}^{\eta \gamma} \exp \left[(1-\gamma) t_{1} \log \left(\frac{p}{\bar{p}}\right)+(1-\gamma)^{2} s_{1}\right] .
\end{gathered}
$$

Dividing (B2) by its right-hand side yields

$$
\begin{gathered}
\frac{1-\delta-\beta}{1-\delta} \omega^{-\delta+\gamma(1-\beta)} \bar{\theta}^{(\beta+\eta) \gamma} \bar{q}^{-\eta \gamma} \exp \left[\gamma t_{1} \log \left(\frac{p}{\bar{p}}\right)+\left(2 \gamma-\gamma^{2}\right) s_{1}\right] \\
+\frac{\beta}{1-\delta} \omega^{-1-\epsilon \beta+\gamma(1-\beta)} L_{0}^{-\epsilon} \bar{a}^{1-\delta} \bar{\theta}^{(\beta+\eta)(\epsilon+\gamma)} \bar{q}^{-\eta(\epsilon+\gamma)} \\
\times \exp \left\{\left[(\epsilon+\gamma) t_{1}+t_{2}\right] \log \left(\frac{p}{\bar{p}}\right)+\left[2(\epsilon+\gamma)+\epsilon^{2}-\gamma^{2}\right] s_{1}+s_{2}\right\}=K .
\end{gathered}
$$

Differentiating this expression with respect to the aggregate price level $p$ yields

$$
\frac{d \omega}{d p}=-\frac{N}{D}
$$

where

$$
\begin{aligned}
N= & \frac{1-\delta-\beta}{1-\delta} \omega^{-\delta+\gamma(1-\beta)} \bar{\theta}^{(\beta+\eta) \gamma} \bar{q}^{-\eta \gamma} \gamma t_{1} p^{-1} e_{1} \\
& +\frac{\beta}{1-\delta} \omega^{-1-\epsilon \beta+\gamma(1-\beta)} L_{0}^{-\epsilon} \bar{a}^{1-\delta} \bar{\theta}^{(\beta+\eta)(\epsilon+\gamma)} \bar{q}^{-\eta(\epsilon+\gamma)} \\
& \times\left[(\epsilon+\gamma) t_{1}+t_{2}\right] p^{-1} e_{2}, \\
D= & \frac{1-\delta-\beta}{1-\delta} \omega^{-\delta+\gamma(1-\beta)-1} \bar{\theta}^{(\beta+\eta) \gamma} \bar{q}^{-\eta \gamma}[-\delta-\gamma(1-\beta)] e_{1} \\
& +\frac{\beta}{1-\delta} \omega^{-2-\epsilon \beta+\gamma(1-\beta)} L_{0}^{-\epsilon} \bar{a}^{1-\delta} \bar{\theta}^{(\beta+\eta)(\epsilon+\gamma)} \bar{q}^{-\eta(\epsilon+\gamma)} \\
& \times[-1-\epsilon \beta+\gamma(1-\beta)],
\end{aligned}
$$


and

$$
\begin{aligned}
& e_{1}=\exp \left[\gamma t_{1} \log \left(\frac{p}{\bar{p}}\right)+\left(2 \gamma-\gamma^{2}\right) s_{1}\right] \\
& e_{2}=\exp \left\{\left[(\epsilon+\gamma) t_{1}+t_{2}\right] \log \left(\frac{p}{\bar{p}}\right)+\left[2(\epsilon+\gamma)+\epsilon^{2}-\gamma^{2}\right] s_{1}+s_{2}\right\} .
\end{aligned}
$$

Note that $D \leqslant 0$ is required by the second-order condition for $\omega$. Simplifying (B4) yields

$$
\begin{aligned}
& \frac{1-\delta-\beta}{1-\delta} \omega^{1-\delta} \gamma t_{1} e_{1}+\frac{\beta}{1-\delta} a^{1-\delta}\left(\frac{\omega^{-\beta} \bar{\theta}^{\beta+\eta} \bar{q}^{-\eta}}{L_{0}}\right)^{\epsilon} \\
& \frac{p}{\omega} \frac{d \omega}{d p}=\frac{\times\left[(\epsilon+\gamma) t_{1}+t_{2}\right] e_{2}}{\frac{1-\delta-\beta}{1-\delta} \omega^{1-\delta}[\delta+\gamma(\beta-1)] e_{1}+\frac{\beta}{1-\delta} \bar{a}^{1-\delta}} . \\
& \times\left(\frac{\omega^{-\beta} \bar{\theta}^{\beta+\eta} \bar{q}^{-\eta}}{L_{0}}\right)^{\epsilon}[\gamma(\beta-1)+1+\epsilon \beta] e_{2}
\end{aligned}
$$

Finally, using

$$
\begin{aligned}
e_{2}= & e_{1} \exp \left[t_{2} \log \left(\frac{p}{\bar{p}}\right)+s_{2}\right] \\
& \times \exp \left[\epsilon t_{1} \log \left(\frac{p}{\bar{p}}\right)+\epsilon^{2} s_{1}\right] \exp \left(2 \epsilon s_{1}\right), \\
E\left[\left(\frac{L}{L_{0}}\right)^{\epsilon} \mid p\right]= & \left(\frac{\omega^{-\beta} \bar{\theta}^{\beta+\eta} \bar{q}^{-\eta}}{L_{0}}\right) \exp \left[\epsilon t_{1} \log \left(\frac{p}{\bar{p}}\right)+\epsilon^{2} s_{1}\right], \\
E\left(a^{1-\delta} \mid p\right)= & \bar{a}^{1-\delta} \exp \left[t_{2} \log \left(\frac{p}{\bar{p}}\right)+s_{2}\right]
\end{aligned}
$$

and defining

$$
\begin{aligned}
& \Psi(p)=\left(\frac{\omega}{\bar{a}}\right)^{1-\delta} E\left[\left(\frac{a}{\bar{a}}\right)^{1-\delta} \mid p\right], \\
& \phi(p)=E\left[\left(\frac{L}{L_{0}}\right)^{\epsilon} \mid p\right] \exp \left(2 \epsilon s_{1}\right),
\end{aligned}
$$

we can write (B5) as

$$
\begin{aligned}
& \frac{1-\delta-\beta}{1-\delta} \gamma t_{1} \Psi(p)+\frac{\beta}{1-\delta} \\
& \frac{p}{\omega} \frac{d \omega}{d p}=\frac{\times\left[(\epsilon+\gamma) t_{1}+t_{2}\right] \phi(p)}{\frac{1-\delta-\beta}{1-\delta}[\delta+\gamma(\beta-1)] \Psi(p)+\frac{\beta}{1-\delta}} . \\
& \times[\gamma(\beta-1)+1+\epsilon \beta] \phi(p)
\end{aligned}
$$

Equation (5) in the text follows immediately. 


\section{Appendix C}

\section{Data Sources}

Industry-specific shares of labor and raw materials in industry value-added pertain to 1971 and are taken from "Manufacturing Industries in Canada: Type of Organization and Size of Establishment," Statistics Canada, Primary Industries Division, Ottawa, 1973.

Industry-specific selling prices are taken from "Industry Price Indexes," Statistics Canada, Prices Division, Ottawa, August 1980.

Industry-specific input prices are taken from "Gross Domestic Product by Industry," Statistics Canada, Industry Product Division, Ottawa, March 1982. Industry-specific union-nonunion relative wage rates are based on industry-specific wage rates in 1971 in selected urban areas, reported in "Wage Rates, Salaries, and Hours of Labour," Labour Canada, Ottawa, 1971.

\section{References}

Blanchard, Olivier J. "Wage Indexing Rules and the Behavior of the Economy." J.P.E. 87 (August 1979): 798-815.

Brown, James N., and Ashenfelter, Orley. "Testing the Efficiency of Employment Contracts." J.P.E., this issue.

Card, David. "Cost-of-Living Escalators in Major Union Contracts." Indus. and Labor Relations Rev. 37 (October 1983): 34-48.

Davis, William M. "Collective Bargaining in 1983: A Crowded Agenda." Monthly Labor Rev. 106 (January 1983): 3-16.

Douty, Harry M. "Cost of Living Escalation Clauses and Inflation." Staff Report. Washington: Council on Wage and Price Stability, 1975.

Ehrenberg, Ronald A.; Danziger, Leif; and San, Gee. "Cost-of-Living Adjustment Clauses in Union Contracts: A Summary of Results." J. Labor Econ. 1 (July 1983): 215-45.

Farber, Henry S. "Individual Preferences and Union Wage Determination: The Case of the United Mine Workers." J.P.E. 86 (October 1978): 923-42.

Fischer, Stanley. "Wage Indexation and Macroeconomic Stability." In Stabilization of the Domestic and International Economy, edited by Karl Brunner and Allan H. Meltzer. Carnegie-Rochester Conference Series on Public Policy no. 5. Amsterdam: North-Holland, 1977.

Garbarino, Joseph W. Wage Policy and Long Term Contracts. Washington: Brookings Inst., 1962.

Gray, Jo Anna. "Wage Indexation: A Macroeconomic Approach." J. Monetary Econ. 2 (April 1976): 221-35.

Hamermesh, Daniel S. "Econometric Studies of Labor Demand and Their Application to Policy Analysis." J. Human Resources 11 (Fall 1976): 507-25.

Heckman, James J. "The Common Structure of Statistical Models of Truncation, Sample Selection and Limited Dependent Variables and a Simple Estimator for Such Models." Ann. Econ. and Soc. Measurement 5 (Fall 1976): 475-92.

Leontief, Wassily W. "The Pure Theory of the Guaranteed Annual Wage Contract." J.P.E. 54 (February 1946): 76-79.

MaCurdy, Thomas E., and Pencavel, John H. "Testing between Competing Models of Wage and Employment Determination in Unionized Labor Markets." J.P.E., this issue. 
Riddell, W. Craig, and Smith, Philip M. "Expected Inflation and Wage Changes in Canada, 1967-81." Canadian J. Econ. 15 (August 1982): 37794.

Taft, Philip. "Collective Bargaining before the New Deal." In How Collective Bargaining Works: A Survey of Experience in Leading American Industries, edited by Harry A. Millis. New York: Twentieth Century Fund, 1945. 
http://www.jstor.org

\title{
LINKED CITATIONS
}

\author{
- Page 1 of 2 -
}

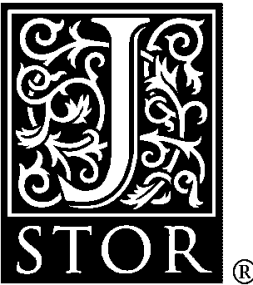

You have printed the following article:

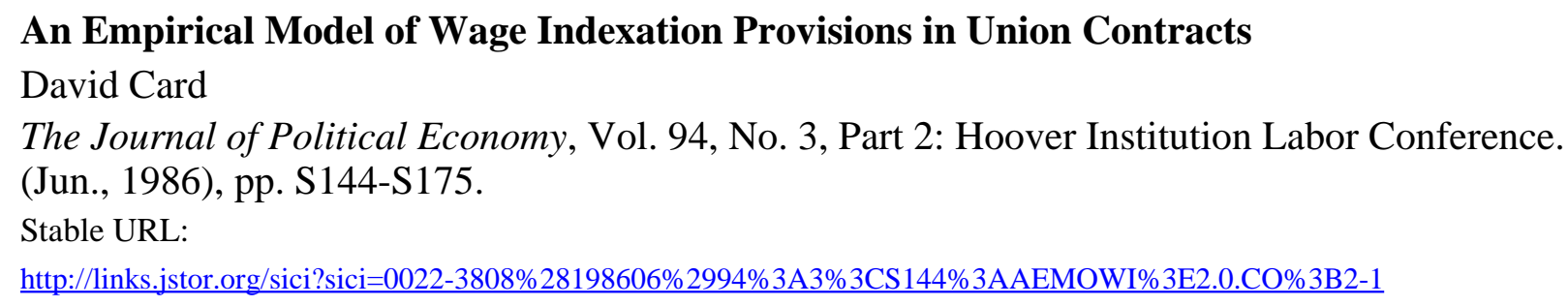

This article references the following linked citations. If you are trying to access articles from an off-campus location, you may be required to first logon via your library web site to access JSTOR. Please visit your library's website or contact a librarian to learn about options for remote access to JSTOR.

\section{[Footnotes]}

\author{
${ }^{31}$ Cost-of-Living Adjustment Clauses in Union Contracts: A Summary of Results \\ Ronald G. Ehrenberg; Leif Danziger; Gee San \\ Journal of Labor Economics, Vol. 1, No. 3. (Jul., 1983), pp. 215-245. \\ Stable URL: \\ http://links.jstor.org/sici?sici=0734-306X\%28198307\%291\%3A3\%3C215\%3ACACIUC\%3E2.0.CO\%3B2-2

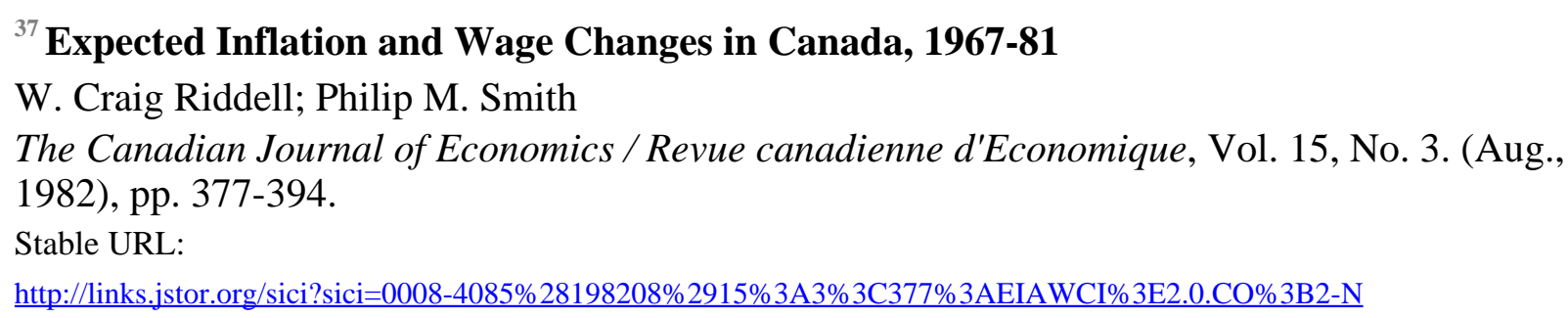

\section{References}

\section{Cost-of-Living Adjustment Clauses in Union Contracts: A Summary of Results}

Ronald G. Ehrenberg; Leif Danziger; Gee San

Journal of Labor Economics, Vol. 1, No. 3. (Jul., 1983), pp. 215-245.

Stable URL:

http://links.jstor.org/sici?sici=0734-306X\%28198307\%291\%3A3\%3C215\%3ACACIUC\%3E2.0.CO\%3B2-2

NOTE: The reference numbering from the original has been maintained in this citation list. 
http://www.jstor.org

\section{LINKED CITATIONS \\ - Page 2 of 2 -}

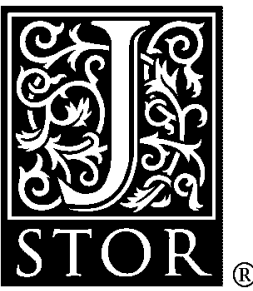

Expected Inflation and Wage Changes in Canada, 1967-81

W. Craig Riddell; Philip M. Smith

The Canadian Journal of Economics / Revue canadienne d'Economique, Vol. 15, No. 3. (Aug., 1982), pp. 377-394.

Stable URL:

http://links.jstor.org/sici?sici=0008-4085\%28198208\%2915\%3A3\%3C377\%3AEIAWCI\%3E2.0.CO\%3B2-N

NOTE: The reference numbering from the original has been maintained in this citation list. 